\title{
Gonatopus jaliscanus sp. n., a new Pincer wasp from Jalisco, Mexico (Hymenoptera, Dryinidae)
}

\author{
Stefano Speranza', Massimo Olmi², Adalgisa Guglielmino', Mario Contarini' \\ I Department of Agriculture and Forest Sciences (DAFNE), University of Tuscia, Viterbo, Italy 2 Tropical \\ Entomology Research Center, Viterbo, Italy \\ Corresponding author: Adalgisa Guglielmino (guglielm@unitus.it)
}

$\frac{\text { Academic editor: } M . O h l \mid \text { Received } 31 \text { October } 2018 \mid \text { Accepted } 18 \text { December } 2018 \mid \text { Published } 17 \text { January } 2019}{\text { http://zoobank.org/CDDB1862-5548-4322-9992-CFB228E7D41E }}$

Citation: Speranza A, Olmi M, Guglielmino A, Contarini M (2019) Gonatopus jaliscanus sp. n., a new Pincer wasp from Jalisco, Mexico (Hymenoptera, Dryinidae). ZooKeys 818: 35-42. https://doi.org/10.3897/zookeys.818.30974

\begin{abstract}
A new species of Gonatopus Ljungh, 1810, G. jaliscanus sp. n., from Jalisco, Mexico, is described and illustrated. In the Neotropical region, G. jaliscanus is similar to G. forestalis Olmi, 1998, but it is distinguished by the black mesosoma (except prothorax, mesoscutum, and mesoscutellum that are yellow), and the metapostnotum being granulated and not rugose; in $G$. forestalis the mesosoma is completely black and the metapostnotum is granulated and strongly rugose. In the Nearctic region, the new species is morphologically similar to $G$. curriei Krombein, 1962, but it is distinguished by the dull and granulated metapostonotum; in G. curriei the metapostnotum is shiny and unsculptured. The new species belongs to Gonatopus group 7 . The keys to the females of the Nearctic and Neotropical species of this group are modified to include the new taxon.
\end{abstract}

\section{Keywords}

Chrysidoidea, Gonatopodinae, keys, taxonomy

\section{Introduction}

Dryinidae (Hymenoptera: Chrysidoidea) are parasitoids and often also predators of leafhoppers, planthoppers and treehoppers (Hemiptera, Auchenorrhyncha) (Guglielmino et al. 2013). They comprise 16 subfamilies, 50 genera and more than 1800 species worldwide (Olmi and Xu 2015, Tribull 2015).

Jalisco is a state of Mexico situated in a transition area between the Nearctic and Neotropical regions. Species of Dryinidae collected in this state can belong to either

Copyright Stefano Speranza et al. This is an open access article distributed under the terms of the Creative Commons Attribution License (CC BY 4.0), which permits unrestricted use, distribution, and reproduction in any medium, provided the original author and source are credited. 
region, so for the identification, researchers have to check the keys of both zoogeographical regions. Dryinidae of the Nearctic and Neotropical regions were studied mainly respectively by Olmi (1984) and Olmi and Virla (2014).

In the Nearctic and Neotropical regions respectively, the genus Gonatopus Ljungh, includes 51 (Olmi 1984, 1987, 1992, 1993, 1995, 2003, 2010, Olmi and Guglielmino 2013) and 127 species (Martins and Domahovski 2017a, b, Martins et al. 2015a, b, Martins and Krinski 2016, Olmi and Guglielmino 2016, Olmi and Virla 2014). For its part, Mexico is inhabited by 135 species of Dryinidae and 25 of Gonatopus (MoyaRaygoza and Olmi 2010, Becerra-Chiron et al. 2017). In 2017 the authors examined a species of Gonatopus collected in Jalisco, Mexico, which is described as new below.

\section{Materials and methods}

The description follows the terminology used by Guglielmino et al. (2016, 2018a, b) and Olmi and Virla (2014). The measurements reported are relative, except for the total length (head to abdominal tip, without the antennae), which is expressed in millimetres. In the descriptions POL is the distance between the inner edges of the lateral ocelli; $\mathrm{OL}$ is the distance between the inner edges of a lateral ocellus and the median ocellus; OOL is the distance from the outer edge of a lateral ocellus to the compound eye.

The term "metapectal-propodeal complex" is here used in the sense of Kawada et al. (2015). It corresponds to the term "metathorax + propodeum" sensu Olmi (1984) and Olmi and Virla (2014). In apterous Gonatopodinae the terms "anterior surface of metathorax + propodeum" and "posterior surface of metathorax + propodeum", sensu Olmi (1984, 1994), Olmi and Virla (2014), Olmi and Xu (2015) and Xu et al. (2013), correspond here respectively to "metapostonotum" and "first abdominal tergum", sensu Kawada et al. (2015).

The types of all Nearctic and Neotropical species of Gonatopus were examined. The material studied in this paper will be deposited in the National Museum of Natural History, Washington, DC, USA (USNM).

The description of the new species is based on the study of only a single specimen. The authors are aware that descriptions of new taxa should normally be based on more individuals. However, Dryinidae are so rare that it is uncommon to collect more than one specimen of each species. In addition, on the basis of the experience and knowledge of the authors, the new species is sufficiently delimited by unique characters to justify its description.

\section{Results}

\section{Genus Gonatopus Ljungh, 1810}

Gonatopus Ljungh, 1810: 161. Type species: Gonatopus formicarius Ljungh, 1810, by monotypy. 
Diagnosis of the genus. Female: Apterous or less frequently macropterous; palpal formula $3 / 2,4 / 2,4 / 3,5 / 2,5 / 3$, or $6 / 3$; pronotum crossed or not by transverse furrow; enlarged claw with distal apex pointed and with one large or small subapical tooth (occasionally subapical tooth absent, then enlarged claw with distal group of lamellae); in fully winged forms, segment 5 of protarsus with more than 20 lamellae; tibial spurs 1/0/1. Male: Macropterous; occipital carina absent or incomplete (in this last case, present behind and shortly on sides of posterior ocelli); occiput concave; temple present; palpal formula $3 / 2,4 / 2,4 / 3,5 / 2,5 / 3$, or $6 / 3$; tibial spurs $1 / 1 / 2$.

\section{Gonatopus jaliscanus sp. n.}

http://zoobank.org/FEDDFE9E-CD12-4AB7-BC5E-7393473EA1A0

Figs 1, 2

Diagnosis. Female apterous, with mesosoma black, except prothorax, mesoscutum and mesoscutellum yellow; palpal formula $6 / 3$; pronotum crossed by strong transverse furrow (Fig. 1B); stalk between pronotum and metapectal-propodeal complex about as long as disc of pronotum; mesoscutum laterally with two pointed apophyses (Fig. 1A); meso-metapleural suture obsolete; mesopleuron and metapleuron granulated, not transversely striate; metapostnotum granulated; first abdominal tergum transversely striate; protarsomere 1 shorter than 4; enlarged claw with one small subapical tooth (Fig. 2).

Description. Female. Apterous (Fig. 1). Length $3.4 \mathrm{~mm}$. Head, prothorax, mesoscutum, mesoscutellum, metasoma and legs testaceous. Antenna testaceous, except antennomeres $8-10$ brown. Metanotum, metapectal-propodeal complex, mesopleuron, metapleuron and petiole black. Antenna clavate. Antennomeres in following proportions: 8:6:21:12:10:8:7:5:5:6. Head excavated, shiny, very weakly granulated. Frontal line complete. Occipital carina absent. $\mathrm{POL}=2 ; \mathrm{OL}=2 ; \mathrm{OOL}=8$. Greatest breadth of lateral ocelli shorter than POL (1:2). Palpal formula 6/3. Pronotum shiny, unsculptured, crossed by strong transverse furrow (Fig. 1B). Mesoscutum laterally with two pointed apophyses (Fig. 1A). Metanotum inclined, not transversely striate, not hollow behind mesoscutellum (Fig. 1B). Metapectal-propodeal complex with metapostnotum dull, granulated. First abdominal tergum granulated and transversely striated. Mesopleuron and metapleuron dull, granulated, not transversely striated. Meso-metapleural suture obsolete. Protarsomeres in following proportions: 13:3:5:20:30. Protarsomeres 2 and 3 produced into hooks. Enlarged claw (Fig. 2) with one small subapical tooth and eleven peg-like hairs, in addition to one bristle. Protarsomere 5 (Fig. 2) with two rows of $16+5$ lamellae extending beyond 0.5 length of protarsomere and distal apex provided with about 17 lamellae. Tibial spurs 1/0/1.

Male. Unknown.

Material examined. Holotype: female, MEXICO: Jalisco, 8.3 mi. S Autlan, Hwy 80, 5000', 8/vii/1984, on Oaks, Oak Forest, JB Woolley (TAMU (to be deposited in USNM)).

Hosts. Unknown.

Distribution. Mexico (Jalisco). 

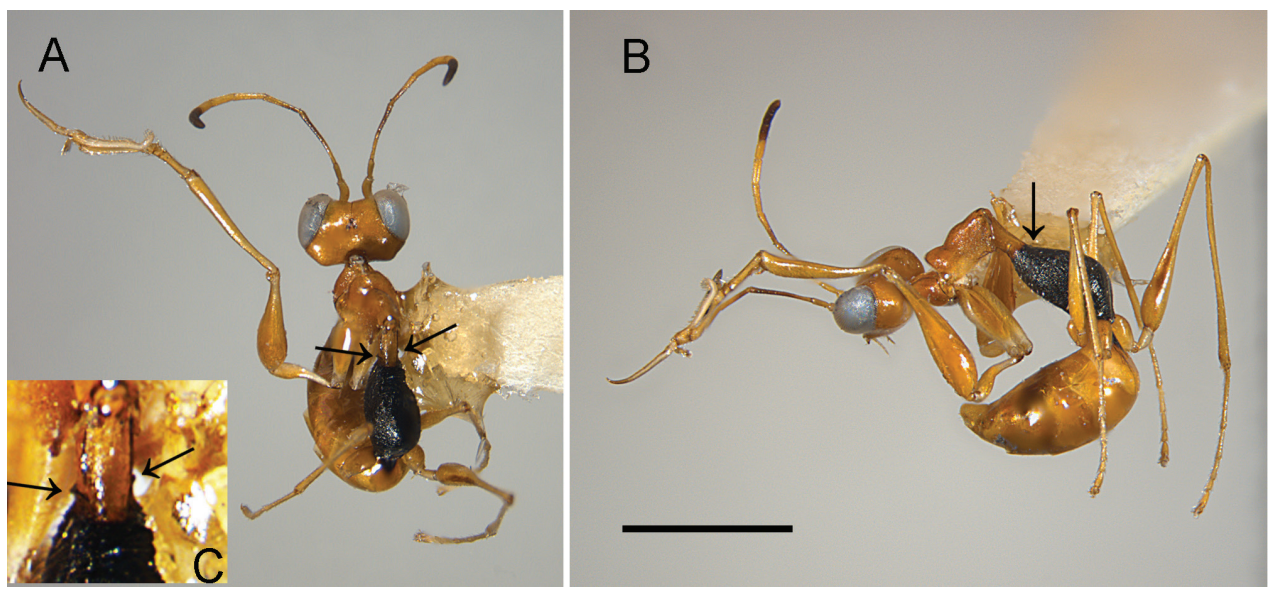

Figure I. Gonatopus jaliscanus sp. n., female holotype: A habitus in dorsal view B habitus in lateral view $\mathbf{C}$ magnification of mesoscutum. Arrows indicate lateral apophyses of mesoscutum $(\mathbf{A}, \mathbf{C})$, and metanotum (B). Scale bars: $1.4 \mathrm{~mm}(\mathbf{A}, \mathbf{B}) ; 0.6 \mathrm{~mm}(\mathbf{C})$.

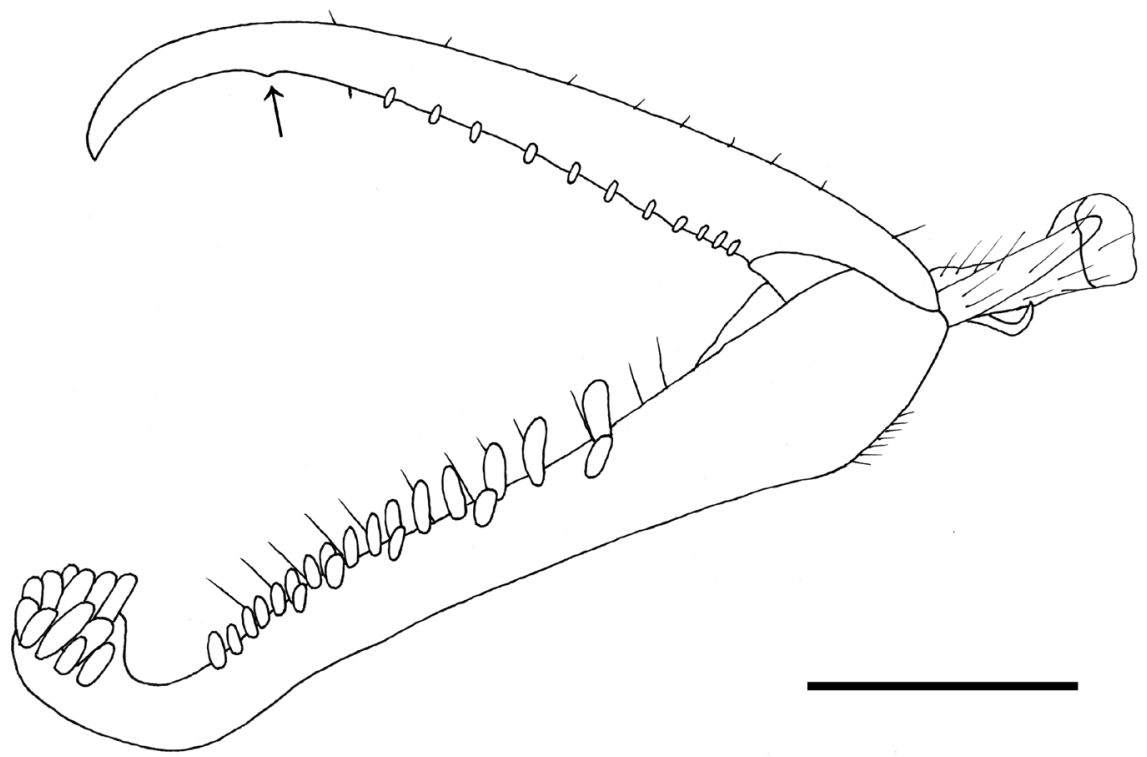

Figure 2. Gonatopus jaliscanus sp. n., female holotype: chela. Arrow indicates the enlarged claw subapical tooth. Scale bar $0.19 \mathrm{~mm}$.

Etymology. The species is named after the state of Jalisco, where the holotype was collected.

Remarks. The female of the new species is apterous, with pronotum crossed by a strong transverse furrow (Fig. 1B), the enlarged claw provided of one small subapical 
tooth (Fig. 2) and the palpal formula 6/3. Because of these characters, G. jaliscanus belongs to group 7 of Gonatopus, according to the systematics proposed by Olmi and Virla (2014). In this species, the head is excavated, the labial palpus is 3-segmented, the mesoscutum has two lateral pointed apophyses situated in the stalk between pronotum and metapectal-propodeal complex (Fig. 1A), the metanotum is sloping anteriorly (Fig. 1B), the meso-metapleural suture is obsolete, the first abdominal tergum is completely transversely striate, the protarsomere 1 is shorter than protarsomere 4 (Fig. 1A). In the Nearctic region, there is only one species of Gonatopus group 7 with the above characters: G. curriei Krombein, 1962. The new species can be included in the key to the females of the Nearctic species of Gonatopus group 7 presented by Olmi (1984) by replacing couplet 30 as follows:

30 Protarsomere 4 slightly shorter than $1 \ldots$ G. argyrias (Perkins)

- $\quad$ Protarsomere 4 longer than 1 30 '

30’ Metapostnotum shiny, unsculptured G. curriei Krombein Metapostnotum dull, granulated G. jaliscanus sp. n.

In the Neotropical region, G. jaliscanus is similar to G. forestalis Olmi, 1998. The new species can be included in the key to the females of the Neotropical species of Gonatopus group 7 presented by Olmi and Virla (2014) by replacing couplet 51 as follows:

51 Mesoscutum laterally with two strong pointed apophyses (Fig. 1A) .........51'

- Mesoscutum laterally without pointed apophyses .................................52

51' Mesosoma totally black; metapostnotum granulated and strongly rugose......

G. forestalis Olmi

- Mesosoma black, except yellow prothorax, mesoscutum and mesoscutellum (Fig. 1); metapostnotum granulated but not rugose

G. jaliscanus sp. n.

\section{Conclusions}

Species of Gonatopus from Mexico are known mainly through the monographs on Dryinidae of the Nearctic (Olmi 1984) and Neotropical regions (Olmi and Virla 2014), the checklist of Moya-Raygoza and Olmi (2010) and the paper of Becerra-Chiron et al. (2017) totalling 25 species of Gonatopus from the country. Following the above description of $G$. jaliscanus, the Gonatopus species known from Mexico now number 26.

In Brazil, there are 31 described Gonatopus species (Olmi and Virla 2014, Martins et al. 2015a, b, Martins and Krinski 2016, Martins and Domahovski 2017a, b); in Costa Rica 22 (Olmi and Virla 2014); and in Argentina 47 (Olmi and Virla 2014). The higher numbers of Gonatopus species from Brazil and Argentina suggest that the true number of species in Mexico will ultimately be much higher. Further research, also on the hosts, will be needed to better characterise this fauna. In fact, hosts are known only for 12 of the 26 Gonatopus species recorded from Mexico (Becerra-Chiron 
et al. 2017, Guglielmino et al. 2013): another gap to be bridged, in spite of the contributions of Prof Moya-Raygoza and his research group (Moya-Raygoza and Olmi 2010, Becerra-Chiron et al. 2017). Among these 12 hosts, leafhopper pests of maize in the Neotropical region are economically important (Guglielmino et al. 2006).

\section{Acknowledgements}

We offer many thanks to Prof James B. Woolley and Dr Karen Wright (Texas A\&M University, College Station, USA) for the loan of the specimen described in this paper. The authors are very grateful to Prof Maurizio Biondi (University of L'Aquila, Italy) for the multifocal pictures of the new species and Mr Bob Zuparko (Essig Museum of Entomology, University of California, Berkeley, California, USA) for his suggestions on the English language of this paper. This research was carried out in the frame of the MIUR (Italian Ministry for Education, University and Research) initiative "Department of excellence" (Law 232/2016) and partially supported by the European Commission under the Grant Agreement number 774571 (project PANTHEON - "Precision farming of hazelnut orchards").

\section{References}

Becerra-Chiron IM, Moya-Raygoza G, Muñoz-Urias A (2017) Host-Dryinidae (Hymenoptera) interactions on edge grasses of maize agroecosystem throughout winter in Mexico. Journal of Hymenoptera Research 57: 155-166. https://doi.org/10.3897/jhr.57.12990

Guglielmino A, Bückle C, Moya-Raygoza G (2006) Description of the larval instars of Gonatopus bartletti Olmi, 1984 (Hymenoptera: Dryinidae). Zootaxa 1226: 51-60.

Guglielmino A, Olmi M, Bückle C (2013) An updated host-parasite catalogue of world Dryinidae (Hymenoptera: Chrysidoidea). Zootaxa 3740: 1-113. https://doi.org/10.11646/ zootaxa.3740.1.1

Guglielmino A, Olmi M, Marletta A, Speranza S (2018a) A new species of the genus Gonatopus Ljungh from the USA (Hymenoptera, Dryinidae). ZooKeys 747: 63-69. https://doi. org/10.3897/zookeys.747.24399

Guglielmino A, Olmi M, Speranza S (2016) Description of Gonatopus sandovalae (Hymenoptera Dryinidae), a New Species from Ecuador. Florida Entomologist 99:437-439. https://doi.org/10.1653/024.099.0314

Guglielmino A, Olmi M, Speranza S (2018b) Description of Gonatopusxui sp. n. from India (Hymenoptera Dryinidae). Redia 101: 31-33. https://doi.org/10.19263/REDIA-101.18.05

Kawada R, Lanes GO, Azevedo CO (2015) Evolution of metapostnotum in flat wasps (Hymenoptera, Bethylidae): implications for homology assessments in Chrysidoidea. PLoS ONE 10(10): e0140051. https://doi.org/10.1371/journal.pone.0140051.

Ljungh SJ (1810) Gonatopus, novum insectorum genus. Beiträge zur Naturkunde 2: 161-163. 
Krombein KV (1962) Natural History of Plummers Island, Maryland, XIII. Descriptions of new wasps from Plummers Island, Maryland (Hymenoptera: Aculeata). Proceedings of the Biological Society of Washington 75: 1-18.

Martins AL, Domahovski AC (2017a) New record of Gonatopus flavoniger Olmi, 1991 (Hymenoptera: Dryinidae), from Paraná, Brazil, with notes on some aspects of its biology and morphology. Check List 13: 95-99. https://doi.org/10.15560/13.4.95

Martins AL, Domahovski AC (2017b) Redescription and biology of Gonatopus amazonicus Olmi (Hymenoptera, Dryinidae) from Southern Brazil. Zootaxa 4324: 592-596. https:// doi.org/10.11646/zootaxa.4324.3.12

Martins AL, Krinski D (2016) First record of the parasitoid Gonatopus flavipes Olmi, 1984 (Hymenoptera, Dryinidae) in Brazil's Amazon forest. Journal of Hymenoptera Research 50: 191-196. https://doi.org/10.3897/JHR.50.8897

Martins AL, Lara RIR, Perioto NW (2015a) New records of Dryinidae (Hymenoptera: Chrysidoidea) from the Atlantic Rainforest of São Paulo, Brazil. Pan-Pacific Entomologist 91: 196-199. https://doi.org/10.3956/2015-91.2.196

Martins AL, Lara RIR, Perioto NW, Olmi M (2015b) Two new species of Dryinidae (Hymenoptera: Chrysidoidea) from areas of Atlantic Rainforest at São Paulo State, Brazil. Brazilian Journal of Biology 75: 455-459. https://doi.org/10.1590/1519-6984.19613

Moya-Raygoza G, Olmi M (2010) A catalogue of Dryinidae of Mexico, with descriptions of the opposite sexes of some species (Hymenoptera Chrysidoidea). Frustula entomologica (2008)(NS) 31: 77-112.

Olmi M (1984) A revision of the Dryinidae (Hymenoptera). Memoirs of the American Entomological Institute 37: 1-12, 1-1913.

Olmi M (1987) New species of Dryinidae (Hymenoptera, Chrysidoidea). Fragmenta Entomologica 19: 371-456.

Olmi M (1992) Contribution to the knowledge of the Gonatopodinae (Hymenoptera Dryinidae). Bollettino dell'Istituto di Entomologia dell'Università di Bologna 46: 109-122.

Olmi M (1993) A new generic classification for Thaumatodryininae, Dryininae and Gonatopodinae, with descriptions of new species (Hymenoptera Dryinidae). Bollettino di Zoologia Agraria e Bachicoltura (Ser. II) 25: 57-89.

Olmi M (1994) The Dryinidae and Embolemidae (Hymenoptera: Chrysidoidea) of Fennoscandia and Denmark (Fauna Entomologica Scandinavica 30). EJ Brill, Leiden, Netherlands, $100 \mathrm{pp}$.

Olmi M (1995) Contribution to the knowledge of the world Dryinidae (Hymenoptera Chrysidoidea). Phytophaga 6: 3-54.

Olmi M (1998) New Embolemidae and Dryinidae (Hymenoptera Chrysidoidea). Frustula entomologica [1997](NS) 20: 30-118.

Olmi M (2003) A contribution to the knowledge of Dryinidae (Hymenoptera Chrysidoidea). Frustula entomologica [2001](NS) 24: 21-49.

Olmi M (2010) A contribution to the knowledge of Dryinidae from the Oriental, Nearctic, Neotropical and Australian regions (Hymenoptera Chrysidoidea). Frustula entomologica [2008](NS) 31: 11-34. 
Olmi M, Guglielmino A (2013) Description of Gonatopus rileyi sp. nov. from Arkansas (Hymenoptera: Dryinidae). Pan-Pacific Entomologist 89: 79-83. https://doi.org/10.3956/2012-60.1

Olmi M, Guglielmino A (2016) Two new species of Gonatopus Ljungh from Ecuador (Hymenoptera: Dryinidae). Euroasian Entomological Journal 15(Suppl. 1): 108-112.

Olmi M, Virla EG (2014) Dryinidae of the Neotropical Region (Hymenoptera: Chrysidoidea). Zootaxa 3792: 1-534. https://doi.org/10.11646/zootaxa.3792.2.1

Olmi M, Xu Z (2015) Dryinidae of the Eastern Palaearctic region (Hymenoptera: Chrysidoidea). Zootaxa 3996: 1-253. https://doi.org/10.11646/zootaxa.3996.1.1

Tribull CM (2015) Phylogenetic relationships among the subfamilies of Dryinidae (Hymenoptera, Chrysidoidea) as reconstructed by molecular sequencing. Journal of Hymenoptera Research 45: 15-29. https://doi.org/10.3897/JHR.45.5010

Xu Z, Olmi M, He J (2013) Dryinidae of the Oriental region (Hymenoptera: Chrysidoidea). Zootaxa 3614: 1-460. https://doi.org/10.11646/zootaxa.3614.1.1 